\title{
O PAPEL DOS INSTRUMENTOS LEGISLATIVOS NA APROPRIAÇÃO DO ENTORNO DO COMPLEXO INDUSTRIAL E PORTUÁRIO DO PECÉM - CIPP PELO MERCADO IMOBILIÁRIO
}

\author{
Francisca Bruna Santiago Viana Cavalcante ${ }^{1}$
}

\section{Resumo}

A implantação do Complexo Industrial e Portuário do Pecém (CIPP) entre São Gonçalo do Amarante e Caucaia - CE resultou na transformação das dinâmicas imobiliárias de seu entorno. Partindo desse ponto, este trabalho busca compreender como o poder público local, através dos instrumentos legislativos a nível municipal, regula a ação recente do mercado imobiliário na área desde a implantação do complexo. Foram levantados os Planos Diretores realizados para os dois municípios e, em seguida, foram identificados e espacializados os grandes empreendimentos imobiliários dentro do recorte espacial estipulado. Ao confrontá-los, se evidencia um cenário em que os órgãos públicos estão afinados com os interesses dos agentes privados, facilitando sua atuação através da flexibilização de parâmetros, agravada pela ausência de intersetorialidade entre os órgãos públicos de planejamento.

Palavras-chave: Complexo Industrial e Portuário do Pecém - CIPP; produção imobiliária; regulação da desregulamentação; Plano Diretor.

\section{THE ROLE OF LEGISLATIVE INSTRUMENTS IN THE SURROUNDINGS OF THE INDUSTRIAL AND PORT COMPLEX OF PECÉM - CIPP APPROPRIATED BY THE REAL ESTATE MARKET}

\begin{abstract}
Placing the Industrial and Port Complex of Pecém (CIPP) between São Gonçalo do Amarante and Caucaia - CE resulted in the real estate dynamics' transformation of its surroundings. From this point, this paper seeks to understand how the local government, through legislative instruments at municipal level, regulates the real estate market's recent action in the área since since its implantation. The municipal Masterplans carried out for the two municipalities were gathered, and then the large real estate developments were identified and spatialized within the set spatial cut. When confronted, there is a scenario in which the local government is in tune with the interests of private agents, easing their performance through the flexibility of parameters, aggravated by the lack of intersectoriality among public planning agencies.
\end{abstract}

Keywords: Pecém Industrial and Port Complex - CIPP; real estate production; regulated deregulation; Municipal Masterplan.

\footnotetext{
${ }^{1}$ Mestranda no Programa de Pós-Graduação em Geografia pela Universidade Federal do Ceará.

E-mail: brunasantiagocavalcante@gmail.com
} 


\section{IL RUOLO DEGLI STRUMENTI LEGISLATIVI NEI DINTORNI DEL COMPLESSO INDUSTRIALE E PORTUALE DI PECÉM - CIPP APPROPRIATO DAL MERCATO IMMOBILIARE}

\section{Resumen}

L'impianto del Complesso Industriale e Portuale di Pecém (CIPP) tra São Gonçalo do Amarante e Caucaia - CE ha portato alla trasformazione delle dinamiche immobiliari dei suoi dintorni. Da questo punto, questo articolo cerca di capire come il governo locale, attraverso gli strumenti legislativi a livello comunale, regola la nuova azione del mercato immobiliare lì dall'impianto del complesso. Sono stati raccolti i Masterplan municipali per i due comuni e quindi i grandi progetti immobiliari sono stati identificati e spazializzati all'interno del determinato taglio spaziale. Quando ci si confronta, c'è uno scenario in cui il governo è in sintonia con gli interessi degli agenti privati, facilitando loro lavoro attraverso la flessibilità dei parametri, aggravata dalla mancanza di intersettorialità tra le agenzie di pianificazione pubblica.

Parole Chiave: Complesso Industriale e Portuale di Pecém - CIPP; produzione del mercato immobiliare; regolazione della deregolamentazione; Masterplan municipale.

\section{CONTEXTUALIZAÇÃO}

A lógica mercadológica está atingindo escalas cada vez mais amplas com o avançar da globalização e do neoliberalismo a partir da segunda metade do século XX. Para inserir-se no mercado mundial, as localidades competem entre si com intuito de se destacarem por suas particularidades que, consequentemente, ofereceriam boas oportunidades a investidores estrangeiros. Uma maneira de atingir esse objetivo seria a construção de megaprojetos turísticos ou infraestruturais, vistos como diferenciais nessa competição pela atração da atenção de grandes agentes econômicos globais. Entretanto, é comum que estas grandes obras transformem de forma radical as paisagens nas quais estão inseridas, trazendo diversos impactos para a população local (GELERT, LYNCH, 2003)

Neste contexto foi idealizado e concretizado o Complexo Industrial e Portuário do Pecém (CIPP), composto por uma área de 13,337ha há cerca de $50 \mathrm{~km}$ da capital do Ceará, na Região Metropolitana de Fortaleza (RMF), entre os municípios de Caucaia e São Gonçalo do Amarante (SGA) (ver Figura 01). Com esse megaprojeto, o Governo do Ceará pretendia atrair indústrias de base para o estado, entendidas como grandes indutoras de desenvolvimento econômico que levariam o estado cearense a se inserir de forma mais competitiva nas redes de comércio marítimo nacionais e internacionais. 
Sem dúvida esse intento está sendo cumprido, destacando-se a taxa de crescimento do porto sempre em ascensão ${ }^{2}$; a quantidade de investimento em indústrias no complexo que totaliza R\$ 28,5 bilhões (AECIPP, s.d.); e as diversas parcerias internacionais em vias de consolidação, como por exemplo com o Porto de Roterdã.

Após esta breve assimilação do porte e relevância do CIPP, é de se esperar que ele tenha causado transformações drásticas em seu entorno. Inclusive, alguns autores já apresentaram muitos desses impactos na esfera ambiental (ver LANDIM NETO, 2016; SILVA et al, 2014) e socioeconômica (ver BORGES, 2014; DEUSDARÁ, 2013; SANTOS, 2013; TELES, 2015). Além disso, a produção imobiliária na região também foi impactada, como já garantia o autor Peyrelongue (2010) ao destacar que portos e complexos industriais podem ser elementos de desenvolvimento regional e, consequentemente, de valorização da terra.

Figura 01: Localização do CIPP e recorte espacial da pesquisa

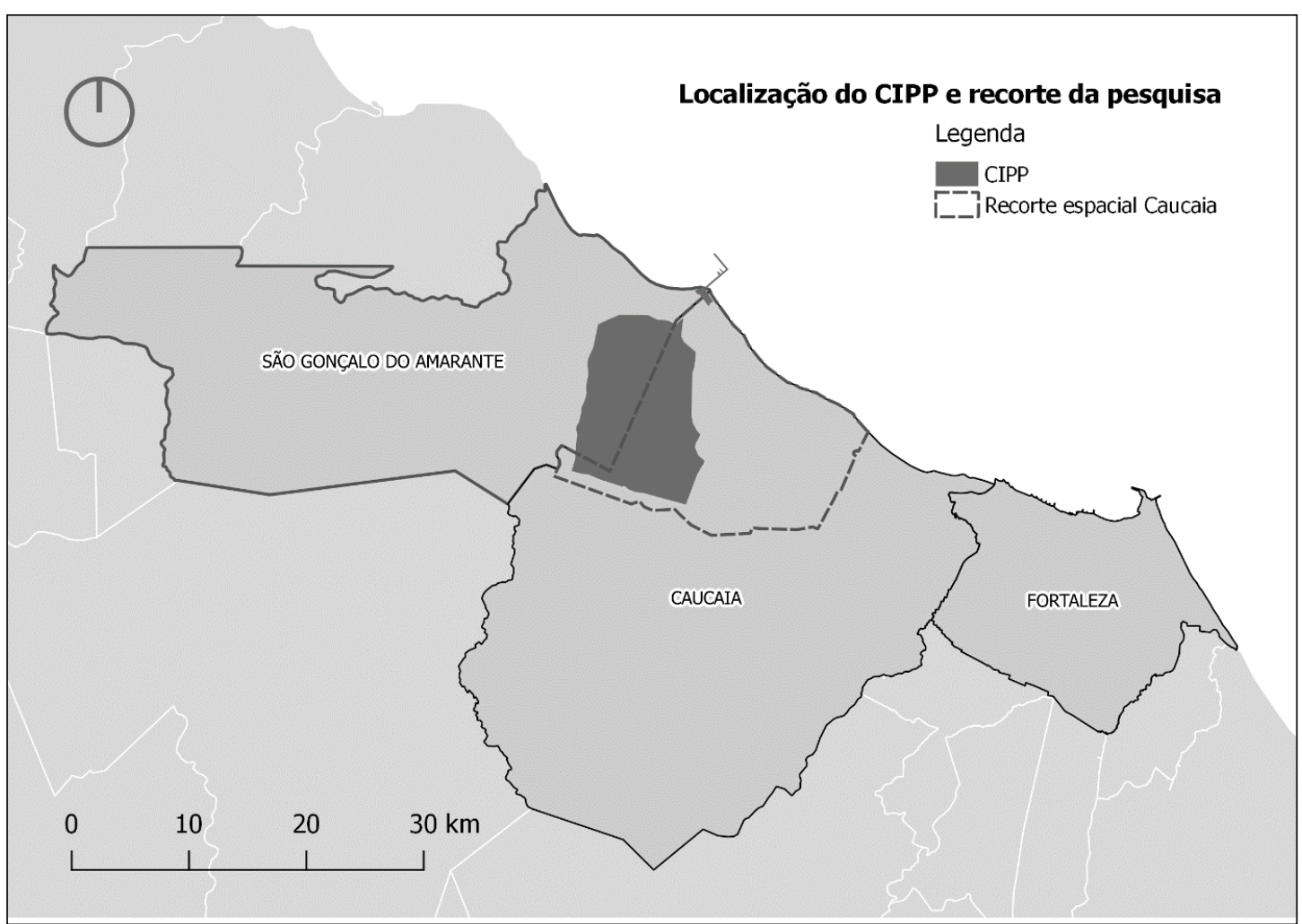

Fonte: Mapa de elaboração própria sobre base do IBGE, 2010.

\footnotetext{
${ }^{2}$ Houve o crescimento de $51 \%$ das importações de 2016 a 2017, e de $243 \%$ das exportações no mesmo período de acordo com a CIPP S.A. (CEARÁPORTOS, 2017).
} 
Com a consolidação do CIPP, o mercado imobiliário local tomou a região como promissora para se investir, tendo em vista que "suas estratégias de apropriação do espaço, relacionam-se com a identificação de condições privilegiadas de obtenção de ganhos" (RUFINO, 2016, p. 253). Proliferaram grandes empreendimentos imobiliários em SGA e na porção noroeste de Caucaia, municípios que anteriormente a todos esses processos apresentavam ocupação urbana e relevância econômica pouco expressivas. Essa ocupação se deu a partir de uma especulação do desenvolvimento econômico, da criação de empregos e do aumento da circulação de pessoas que o complexo traria no futuro.

De fato, muitos empregos foram criados pelo porto e pelas indústrias que lá se instalaram ${ }^{3}$, entretanto a ocupação desses grandes loteamentos construídos na região, majoritariamente residenciais, não se deu imediatamente, resultando numa paisagem inóspita, composta por muitos lotes vazios ainda não ocupados por seus compradores. Isso se dá em parte porque alguns enxergam a região apenas como investimento e não pretendem morar no lote adquirido. Essa prática é fortemente encorajada pelos próprios corretores imobiliários e incorporadoras a partir do momento que o material publicitário elaborado explora o conteúdo mercadológico da casa, além do seu caráter sociocultural, de forma semelhante ao que acontece em Fortaleza (RUFINO, 2016). Adquirir lotes com o objetivo único de gerar renda em cima do investimento desencadeou um processo de especulação imobiliária sobre a promessa de valorização da terra na região, legitimado pelo discurso do Governo do Estado do Ceará de que o CIPP continuará trazendo prosperidade para a área.

Ou seja, o parcelamento avassalador e veloz do entorno do CIPP foi feito por agentes que visam principalmente o lucro com base na especulação de que aquela área continuará a se valorizar, priorizando acima de tudo o caráter da terra de mercadoria, como observado por Topalov em outros contextos (1979). No mundo, este processo não é novo, tendo em vista que Harvey já o identificava desde a década de 80 (AALBERS, 2015). A terra passa a ter caráter de mercadoria e seu valor e potencial valorização colocam em segundo plano seus atributos de uso básicos como sua função social, conceito importante para discutir direito à moradia (ROLNIK, 2015). Essa postura é incentivada inclusive pelo poder público, pois valorização de terras é vista como sinônimo de progresso (RUFINO, 2016).

Uma das formas que o poder público teria de favorecer a expansão do mercado imobiliário sobre o território seria através da regulação da desregulamentação ${ }^{4}$, conceito trazido

\footnotetext{
${ }^{3} 23$ mil diretos e indiretos, de acordo com dados do Anuário do Ceará 2018-2019 do Jornal O Povo (2018).

4 "Regulated deregulation", no original. Tradução utilizada por Rosa et al. (2018).
} 
por Aalbers (2016), que explica que ainda há regulação sobre o mercado, mas ao mesmo tempo alguns agentes tem mais liberdade do controle governamental que outros.

A partir daí, surge o questionamento de como de como as secretarias responsáveis pelo planejamento urbano de SGA e Caucaia regulam a visível tendência especulativa no entorno do CIPP. As legislações de ordenamento territorial seriam uma forma de fazê-lo, entretanto coloca-se sobre a mesa a hipótese de que a legislação facilita a ação dos agentes imobiliários na região, o que explicaria o boom imobiliário tão veloz ocorrido principalmente nos últimos 6 anos.

Sendo assim, o objetivo deste trabalho é compreender como o poder público municipal, através dos instrumentos normativos, modera a ação recente do mercado imobiliário em SGA e Caucaia desde a implantação do CIPP. Apesar de existirem diversas normativas regentes do ordenamento territorial em várias escalas, o foco deste artigo se detém nos seus Planos Diretores, principais normativas a nível municipal. O recorte espacial dessa análise abrangerá SGA como um todo e a porção noroeste de Caucaia (ver Figura 01), já que o restante do município sofre maior influência de Fortaleza.

Os objetivos específicos são:

- Reunir os Planos Diretores vigentes em SGA e Caucaia desde a década de 1990, quando se iniciam as obras do CIPP;

- Entender a interação entre essas legislações;

- Fazer um levantamento dos grandes empreendimentos imobiliários que estão surgindo na região;

- Observar como a realização desses empreendimentos foi influenciada pelos Planos Diretores, e vice-versa.

Para atingir os objetivos, foram levantados os Planos Diretores de Desenvolvimento Urbano de Caucaia e SGA, o Plano Diretor Participativo de SGA e os decretos aprovados posteriormente que os modificam. A breve descrição desses documentos corresponde ao segundo item deste artigo. É importante destacar que os zoneamentos dessas normativas foram especializados e georreferenciados com a ajuda do software QGIS para facilitar a análise. Para compreender melhor como se dá na prática a aplicação dos Planos Diretores, também foram realizadas algumas entrevistas semiestruturadas com funcionários das secretarias de meio ambiente e urbanismo dos dois municípios (SEMURB-SGA e SEPLAM-Caucaia, realizadas 
em 28/08 e 06/09/2018 respectivamente); com uma corretora imobiliária de tradição da área (da Flat Shop Imóveis, realizada em 09/10/2018); e com arquitetos que estavam presentes no processo de elaboração dos Planos Diretores dos dois municípios (Fausto Nilo, entrevistado em 14/05/2019; e Renato Pequeno, entrevistado em 18/06/2019).

Em seguida, os empreendimentos imobiliários foram identificados no item seguinte, dentre eles loteamentos abertos, condomínios de lotes fechados e resorts. O recorte temporal desse levantamento parte de 1995, quando o CIPP começa a ser prospectado, até agosto de 2018, quando o Pecém e o Porto de Roterdã anunciam sua parceria. Esse período foi escolhido devido uma suspeita inicial de que os marcos importantes na história do complexo influenciariam nos picos de atividade imobiliária nas suas proximidades. Os empreendimentos deveriam apresentar pelo menos 1 ha de área ${ }^{5}$ para serem considerados causadores de impacto considerável no espaço, resultando num total de 29 amostras. Algumas variáveis relacionadas às suas implantações, características formais, relação com as normativas e estratégias de marketing utilizadas em suas vendas foram coletadas principalmente em visitas de campo e em material publicitário online. Para além da caracterização dos empreendimentos, a partir de seu mapeamento foi possível também o cruzamento com os zoneamentos dos planos, possibilitando as análises trazidas neste artigo apresentadas no quarto item, para enfim caminhar-se às considerações finais.

O presente artigo faz parte de uma pesquisa maior que investiga a produção imobiliária no entorno do CIPP numa perspectiva multi e interescalar. Se inicia com a contextualização do cenário que tornou possível a implantação do CIPP; passando para a apresentação dos principais agentes envolvidos com a nova produção imobiliária na área; até chegar num levantamento das legislações ambientais e de ordenamento territorial encontradas em várias escalas. Em seguida, caracteriza os empreendimentos levantados até por fim discutir a sua interação com as normativas e os impactos que são causados por conta dessa veloz ocupação do território pelo mercado imobiliário. Por isso, aqui são registrados os agradecimentos à CAPES/FUNCAP pelo apoio à pesquisa.

\footnotetext{
${ }^{5}$ Usando como referência o Projeto de lei $\mathrm{n}^{\mathrm{o}} 3.057$ de 2000 que considera como loteamentos de pequeno porte os que possuem área menor que 1ha, por isso, não tão relevantes ou impactantes para a pesquisa. Além disso, esse é o padrão de empreendimento mais comum na área desde a concretização do CIPP.
} 


\section{Normativas de ordenamento territorial municipais no entorno do CIPP}

Por muito tempo a lei federal $\mathrm{n}^{0} 6.766$ de 1979 foi a principal normativa que regia sobre o ordenamento territorial no país. Porém, mais recentemente surge o Plano Diretor como instrumento capaz de tratar da realidade particular de cada município, possibilitando também o direcionamento do desenvolvimento urbano e a garantia da função social da propriedade. Se colocando como "o instrumento básico da política de desenvolvimento e expansão urbana" (OLIVEIRA, 2001, p. 18), obrigatório para cidades com mais de 20 mil habitantes ou integrantes de regiões metropolitanas, se originou na Constituição Federal de 1988. Porém, sua implementação se deu a partir da Lei federal $n^{0} 10.257$ de julho de 2001, mais conhecida como Estatuto da Cidade.

Devido à política modernizadora das instituições normativas dos municípios estratégicos para a economia do Ceará, 44 Planos Diretores de Desenvolvimento Urbano (PDDUs) foram elaborados antes mesmo da aprovação do Estatuto da Cidade, no final da década de 1990 e início dos anos 2000. Os dois municípios que são foco desta pesquisa os tiveram elaborados nesse momento, justamente porque o CIPP já tomava forma enquanto o Governo do Ceará prospectava um grande crescimento para o complexo e seu entorno. No geral, eles tratavam apenas da zona urbana e traziam, além das leis mais conhecidas de uso e ocupação do solo e código de obras, planos estratégicos. O Planejamento Estratégico se inspira fortemente no funcionamento de uma empresa, inserido no contexto da competitividade entre os lugares para atração de investimentos originários dos circuitos globais. Sua base são valores básicos como a eficiência, a objetividade, a racionalidade, a flexibilidade e a eficácia, considerando que o desenvolvimento social e o econômico são correspondentes. Contudo, as subjetividades locais não são esquecidas, na verdade são ajustadas para manifestar novos conteúdos e atuarem como diferencial do lugar, dando novos significados à cidade de acordo com valores de um grupo específico, não necessariamente correspondentes à demanda coletiva (NOVAIS, 2010).

Os Planos Estratégicos de SGA e Caucaia são compostos pelo levantamento dos pontos atrativos e fragilidades de cada município, sugerindo soluções que variavam entre: a sugestão do investimento em micro empresas e a capacitação da população local, visando a criação de uma cultura empreendedora na população; a proteção e preservação das potencialidades naturais visando o investimento no turismo; o fortalecimento das atividades 
industriais e agropecuária; a modernização das atividades terciárias com o intuito de gerar oportunidades de negócios.

O PDDU-SGA foi finalizado em 2000 pelo escritório Fausto Nilo Arquitetura e defende principalmente a promoção do desenvolvimento do município através da distribuição equilibrada dos habitantes no território e dos serviços públicos; da melhoria da acessibilidade de seus habitantes entre aglomerações urbanas e da conservação do patrimônio histórico e ambiental visando a criação de uma imagem positiva da cidade. Vale destacar que esse plano foi elaborado sobre uma tentativa de participação popular. Já o PDDU-Caucaia é de 2001, elaborado pelo escritório PPAU, e tem como objetivos gerais disciplinar a ocupação do solo urbano em consonância com a função social da propriedade urbana, buscando atender as carências básicas da população, além de destacar a proteção as áreas de interesse ambiental.

A falta de diálogo ${ }^{6}$ entre os dois escritórios na época da elaboração desses planos resultou em duas legislações distintas entre si, principalmente levando em consideração que o de Caucaia assume uma postura muito mais de planejamento interescalar, enquanto o de SGA sustenta totalmente a solução dos problemas do município num redesenho da morfologia urbana. Isso é claro quando descrevemos as estratégias de planejamento: em Caucaia, há a intenção de se trabalhar de forma interescalar de forma que as Unidades Territoriais de Planejamento (UTP), macro unidades de tamanhos variáveis, definam diretrizes para áreas relativamente homogêneas entre si. Essas UTPs são subdivididas em áreas menores, também de tamanho, as Unidades de Planejamento. Elas estipulam parâmetros urbanísticos de acordo com as suas especificidades locais e com as diretrizes gerais da UTP da qual ela faz parte.

Já SGA trabalha com um macrozoneamento do município que pouco se relaciona com as Unidades de Vizinhança (UV), estipuladas em raios entre 400 a $600 \mathrm{~m}$ que devem abarcar cerca de 7 a 15 mil habitantes. Essas UVs buscam estimular a criação de pequenas centralidades na escala da comunidade, tendo como princípios fundamentais o uso misto, a densidade decrescente no sentido centro-periferia e o estímulo ao deslocamento a pé e de bicicleta, direcionando o fluxo de veículos motorizados a interligar as UVs entre si.

Mesmo com essas incompatibilidades, os Planos Diretores foram postos em prática, até que 10 anos após sua aprovação tiveram de ser revistos, como manda o Estatuto da Cidade. O novo Plano Diretor de Caucaia chegou a ser parcialmente elaborado, porém teve um atraso

\footnotetext{
${ }^{6}$ De acordo com entrevista com Fausto Nilo, realizada em 14/05/2019.
} 
na sua finalização por conta de uma mudança de gestão municipal. Hoje ele continua sendo revisto sem previsão de lançamento, e enquanto isso o PDDU de 2001 é ainda utilizado, mesmo que seu conteúdo esteja desatualizado. Além disso, seu texto foi adaptado por $24 \operatorname{decretos}^{7}$ que o modificam em diversos pontos, especialmente no redesenho dos limites ou até a total reformulação do conteúdo de zonas; modificação de parâmetros urbanísticos; estipulação de projetos especiais que permitem a construção de tipologias na época ilegais ${ }^{8}$ como o condomínio de lotes fechado; e a permissão de novos usos em certas áreas do município.

Já o PDDU-SGA foi atualizado pelo Plano Diretor Participativo de SGA (PDP-SGA) de 2013, realizado dessa vez pela própria Secretaria do Meio Ambiente e Urbanismo do município (SEMURB). Apesar de terem sido mantidos a participação social na elaboração do texto e o planejamento urbano a partir do redesenho da morfologia urbana pelas UVs, houveram algumas mudanças. A primeira delas foi a queda de qualidade dos parâmetros urbanísticos, já que o de 2000 determinava valores específicos para gabarito, lote mínimo, testada e profundidade do lote, índice de aproveitamento, taxa de ocupação e taxa de permeabilidade, variando de acordo com a zona em que se localizava e o uso que a nova edificação teria. $\mathrm{O}$ mesmo vale para o PDDU-Caucaia, minucioso em determinar diferentes parâmetros para cada unidade de planejamento de acordo com as diretrizes da sua UTP, além de se aproximar da escala local através de especificações detalhistas, como até a arborização de calçada. Porém, o PDP-SGA homogeneíza o território ao determinar os mesmos lote mínimo e gabarito para todo o município, desconsiderando as particularidades de cada distrito gonçalense.

Para além disso, em muitos pontos o PDP flexibiliza seus próprios parâmetros, enfraquecendo o seu cumprimento na prática. Um exemplo é o seguinte artigo do Código de Obras e Edificações:

Art. $8^{\circ}$ As edificações residenciais unifamiliares e bifamiliares, desde que mantidas as condições de salubridade e higiene da habitação, ficam dispensadas das seguintes exigências:

a) Área mínima das unidades;

b) Dimensões mínimas das circulações;

c) Dimensões mínimas dos vãos de acesso;

\footnotetext{
${ }^{7}$ Leis $\mathrm{n}^{\mathrm{o}} 1.570$ de $2003 ; 1.641$ de $2005 ; 1.798$ de 2006; 1.997, 2.018, 2.042, 2.057, 2.069 e 2.107 de 2009; 2.138, $2.142,2.153$ e 2.162 de $2010 ; 2.211,2.248$ e 2.249 de $2011 ; 2.292,2.295$ e 2.384 de $2012 ; 2.417,2.424,2.425$ e 2.460 de 2013.

${ }^{8} \mathrm{O}$ condomínio fechado não era previsto em nenhuma legislação federal até sua aprovação na Lei $\mathrm{n}^{\circ} 13.465$ de 2017. Mesmo assim, esse tipo de parcelamento do solo se espalhou por Caucaia e SGA através da criação em seus Planos Diretores e legislações especiais de categorias de projeto excepcionais.
} 
d) Dimensões mínimas dos compartimentos;

e) Dimensões mínimas dos vãos de iluminação e ventilação;

f) Dimensões mínimas dos reservatórios de água;

g) Atendimento às normas técnicas de acessibilidade;

h) Soma da área de projeção máxima de edículas (SÃO GONÇALO DO

AMARANTE- CE, 2013, p.4).

Entretanto, não são esclarecidas quais são as condições mínimas de salubridade e higiene da habitação, abrindo margem para diferentes interpretações que enfraquecem a regulação do ordenamento territorial. É importante destacar que esse problema é recorrente em toda a RMF, mesmo que em diferentes graus, pois, de acordo com Rufino (2016, p. 268),: "a fragilidade institucional dos municípios periféricos da RMF favorece a flexibilização dos parâmetros urbanísticos e ambientais, permitindo a aprovação dos grandes empreendimentos e uma apropriação mais intensa das características naturais da região".

Sobre a gestão do CIPP, por ser um conjunto de equipamentos instalado na fronteira dos dois municípios, seria necessária uma gestão intermunicipal ou pelo menos a cooperação entre as duas prefeituras no momento no delineamento de suas legislações urbanísticas. Os dois Planos Diretores apenas delimitam o complexo sem realmente legislar sobre a área. O zoneamento PDP-SGA chega até o extremo de desconsiderar totalmente os elementos presentes dentro da poligonal correspondente à área industrial, dentre eles corpos d'água de dimensões relevantes (ver Figura 02). Segundo os funcionários da Secretaria Municipal de Planejamento Urbano e Ambiental (SEPLAM) de Caucaia ${ }^{9}$, a gestão do CIPP é feita pela instância Estadual e não houve qualquer diálogo com o poder local, já que essas informações teriam sido guardadas "a sete chaves" para garantir a "competitividade" das indústrias instaladas no complexo.

Figura 02: Comparação entre o zoneamento do PDP-SGA com a localização de corpos

\footnotetext{
${ }^{9}$ Yana e Marcelo, entrevistados em 06/09/2018.
} 


\section{d'agua.}

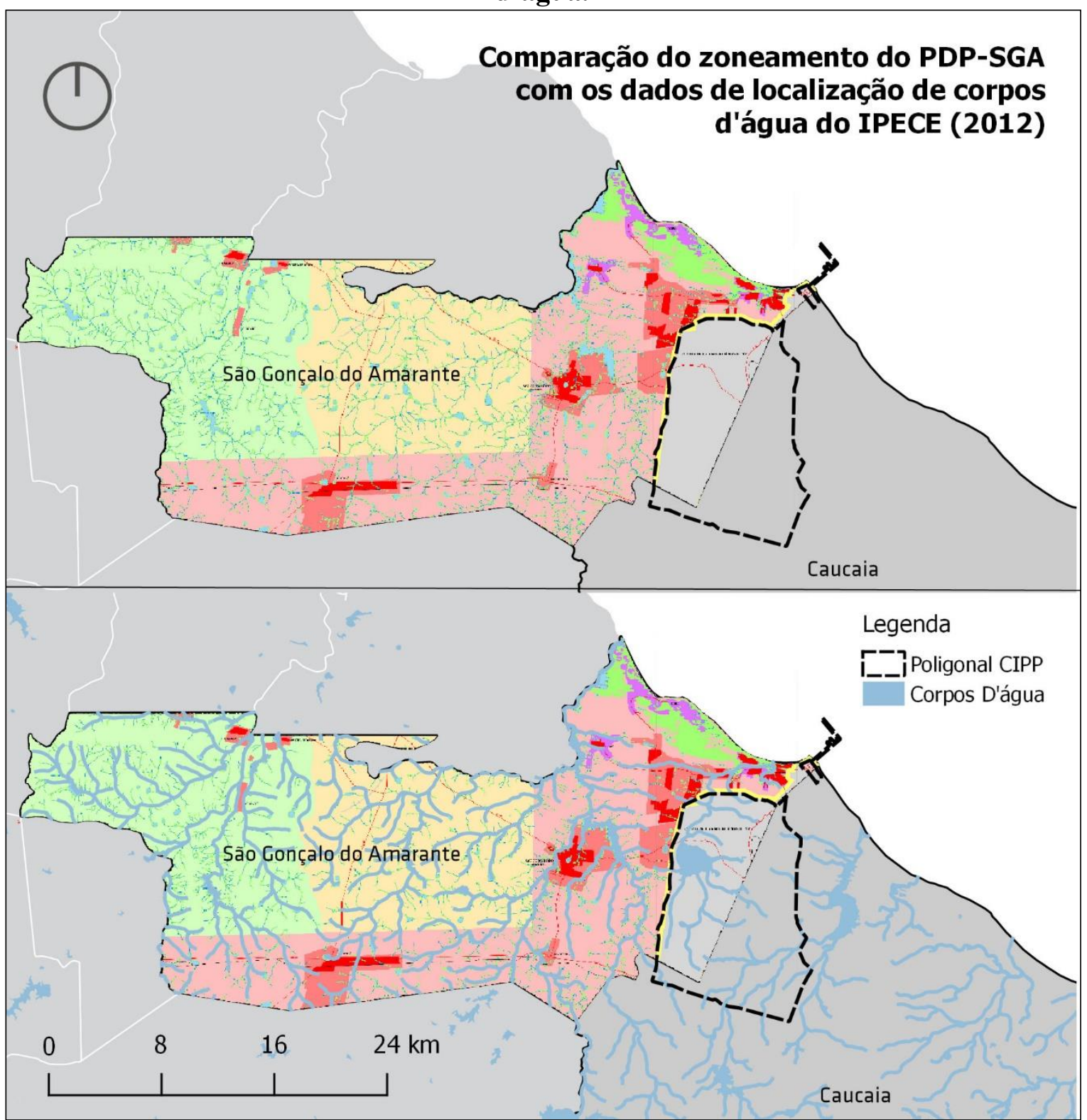

Fonte: Mapa de elaboração própria utilizando a base do Censo IBGE 2010 sobreposta ao zoneamento do PDPSGA (2013) e a dados do IPECE (2012).

Enquanto isso, a falta de diálogo que também acontece entre os órgãos da escala municipal durante a elaboração dos PDDUs resultou na descontinuidade do zoneamento dos municípios, já que as áreas correspondentes ao CIPP se complementam, mas ao sul uma mesma porção de terra é considerado zona rural e industrial pelo PDDU-Caucaia, e ao simples transpor da fronteira se torna zona de expansão urbana por conta da resolução PDP-SGA, o que pode causar conflitos num futuro adensamento dos dois municípios. Essa ausência de 
intersetorialidade entre as prefeituras parece se manter mesmo hoje, já que a revisão do Plano Diretor de Caucaia está sendo realizado novamente sem a integração com SGA ${ }^{8}$.

Por último, o Estatuto da Cidade determina que os Planos Diretores "interfiram no processo de desenvolvimento (urbano) local, a partir da compreensão integradora dos fatores políticos, econômicos, financeiros, culturais, ambientais, institucionais, sociais e territoriais que condicionam a situação encontrada no Município" (OLIVEIRA, 2001, p. 18). Esse processo pode ser feito com a ajuda de diversos instrumentos apresentados pelo próprio estatuto. Muitos deles são citados no corpo do texto dessas duas legislações, inclusive no de Caucaia que é anterior ao Estatuto, como o IPTU Progressivo, Tombamento e Direito de Preempção. O plano de SGA se destaca por ter feito uma tentativa de participação popular na sua elaboração e por citar o Estudo de Impacto de Vizinhança (EIV) e as Zonas Especiais de Interesse Social (ZEIS), dois instrumentos que poderiam ser boas formas de conter um avanço descomedido do mercado imobiliário sobre as terras da parcela da população de baixa renda. Entretanto, nos dois casos os instrumentos não foram regulamentados, impedindo a sua aplicação efetiva.

Após essa breve caracterização dos principais instrumentos que o poder público local tem em mãos para regular a nova produção imobiliária no entorno do CIPP, o item a seguir fará uma breve caracterização de como se deu na prática esse recente boom imobiliário na área.

\section{Os grandes empreendimentos imobiliários}

A ocupação do entorno do CIPP pelo setor imobiliário se deu principalmente nos últimos 6 anos a partir de três tipos distintos de parcelamento do solo, distribuídos entre 29 empreendimentos que variam de 1 a 437ha (ver Figura 03). O primeiro deles é o loteamento aberto residencial, composto em sua maioria por lotes para unidades unifamiliares. Dependendo do porte do loteamento e do seu público alvo, seus equipamentos urbanos e áreas de lazer variam em número e sofisticação. O segundo tipo são os condomínios fechados de lotes, geralmente voltados para públicos de renda mais alta. Focados em garantir segurança para seus moradores, são cercados e têm com acesso controlado através de portarias $24 \mathrm{~h}$ e/ou ronda armada. Por último, os condomínios de edificações se confundem com resorts e estão localizados principalmente no município de Caucaia, de tradição turística maior, principalmente na praia do Cumbuco. Se assemelham aos condomínios fechados, porém verticalizados, ainda reforçando a segregação espacial ao se auto enclausurarem atrás de seus muros. Além disso, possuem uma variedade maior de equipamentos, oferecendo aos seus 
hóspedes serviços sofisticados pay-per-use e atendimento personalizado para turistas estrangeiros. Apesar de voltados para a locação por temporada, algumas de suas unidades estão disponíveis à venda e passaram a ser adquiridas por corporativos do CIPP que gostariam de morar mais próximo ao trabalho e ao mesmo tempo ter acesso à serviços luxuosos que um resort poderia oferecer, como nos conta em entrevista a representante da Imobiliária local Flat Shop ${ }^{10}$.

Figura 03: Localização dos empreendimentos levantados pela pesquisa no município de SGA e no recorte espacial de Caucaia.

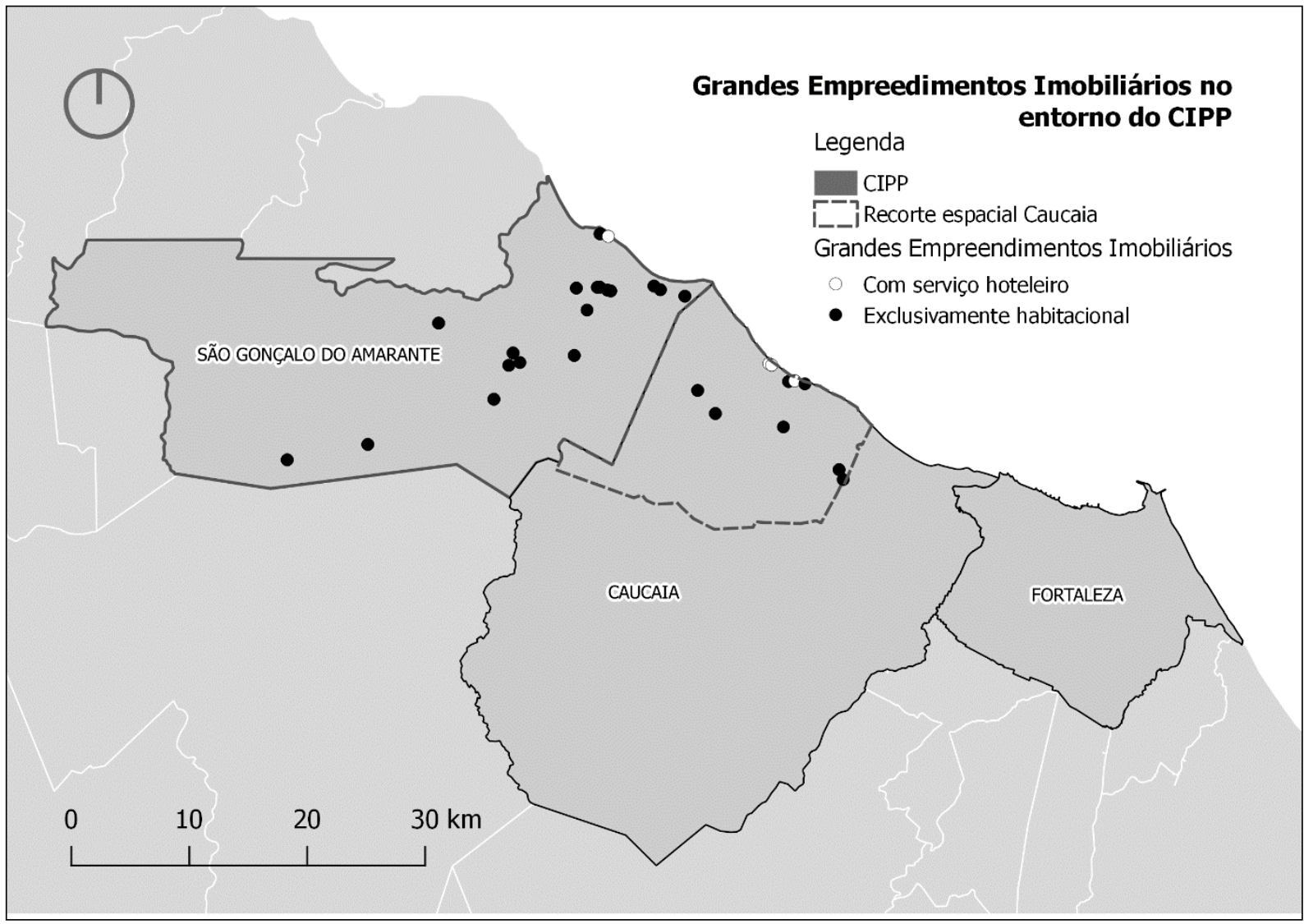

Fonte: Mapa de elaboração própria sobre base do IBGE, 2010.

Dentre o universo de empreendimentos levantados, alguns poucos apresentam agentes estrangeiros atuantes no processo de incorporação, indicando o início de um processo de apropriação de agentes globais da local. Dois exemplos são os loteamentos Smart City Laguna que foi projetado por uma empresa italiana; e o Taíba Beach Resort de capital norueguês.

${ }^{10}$ Carmen, entrevistada em 09/10/2018. 
Apesar de todos os tipos de empreendimentos terem se beneficiado com o crescimento da região, o CIPP e seu porto só são citados nos programas publicitários dos loteamentos residenciais, enquanto aqueles majoritariamente turísticos preferem destacar as belas características naturais da região. Tranquilidade, proximidade à natureza, preservação ambiental, qualidade de vida e segurança são termos recorrentes no discurso do corretor imobiliário, reforçando o valor simbólico da unidade habitacional ou para estadia. Como identificado de forma semelhante em Fortaleza por Rufino (2016), os empreendimentos imobiliários da região são resultado da nova interpretação do "condomínio residencial" pelo mercado imobiliário local ao produzir um maior número de unidades agrupadas a outros diversos usos e serviços, criando um espaço diferenciado. Esse movimento leva inclusive à privatização ilegal do espaço que deveria ser público nos loteamentos e empreendimentos hoteleiros fechados.

Por fim, chegamos à questão chave deste trabalho: alicerçado no contexto da especulação, mercantilização da terra e da busca desenfreada pelo lucro, o mercado imobiliário local e estrangeiro ocupa os municípios de SGA e Caucaia de forma veloz. Como foi visto nos itens anteriores, existem Planos Diretores para os dois municípios que, em sua essência, deveriam tornar possível um ordenamento territorial que assegurasse "o atendimento das necessidades dos cidadãos quanto à qualidade de vida, à justiça social e ao desenvolvimento das atividades econômicas" (BRASIL, 2001, art. 39). O próximo item traz a relação entre essas legislações e os empreendimentos levantados.

\section{A regulação da ocupação do espaço no entorno do CIPP pela legislação}

A partir do cruzamento entre o que foi determinado nos Planos Diretores e como se deu na prática a ocupação do entorno do CIPP, percebeu-se que a questão gira entorno principalmente da regulação da desregulamentação discutida por Aalbers (2016). Esse conceito consiste na afirmação de que, no geral, existem instrumentos normativos que regulamentam o mercado, porém há uma convicção por parte dos agentes neoliberalistas de que a ação do Estado limita negativamente a ação do mercado, mesmo que isso seja contraditório, já que muitas vezes o próprio Estado que cria as condições favoráveis para que a economia se desenvolva. Como estratégia de diminuir a ação do poder público de forma não tão evidente, é dado a agentes selecionados uma maior liberdade de atuação. 
O exemplo mais polêmico constatado foi a aprovação da Lei no 2.248 , de 10 de agosto de 2011, que modifica o PDDU-Caucaia em 3 aspectos: (i) cria a categoria Condomínio Resort/Residencial, tendo em vista a irregularidade de condomínios fechados antes de 2017; (ii) regulamenta as construções no subsolo, que seria futuramente usado pelos empreendimentos hoteleiros como o WaiWai Cumbuco Residence; (iii) e libera a ocupação sobre área de preservação ambiental definida no zoneamento do PDDU nas proximidades do Cumbuco. Atualmente, nas terras em que ocorreram essas mudanças de uso foram construídos os grandes resorts da franquia Vila Galé, além dos Condomínios fechados WaiWai Cumbuco Residence e Summerville Residence Cumbuco.

Isso se repete na UTP 6, ou do Cauype, mais próxima à poligonal do CIPP. Sua descrição reforça sua alta relevância ambiental, por isso alguns de seus trechos mais próximos ao Lagamar do Cauípe foram originalmente marcados como áreas de Preservação e Proteção Ambiental. Uma forma que o plano de Caucaia teve de frear a futura apropriação do mercado imobiliário sobre essas áreas foi permitir apenas o parcelamento do solo em grandes lotes, variando entre 1000 a $5000 \mathrm{~m}^{2}$ de área. Esse tipo de lote não é comumente comercializável pelo mercado imobiliário em loteamentos, por isso seria uma forma de fazer com que não houvesse interesse econômico nessas áreas ${ }^{11}$. A quantidade de pavimentos permitidos também era pouca, variando de 2, atingindo até 4 pavimentos. Contudo, posteriormente os decretos $n^{\circ} 1.570$ de 2003 e n 2.292 de 2012 viriam a modificar esses parâmetros para lotes menores, de 350 até $200 \mathrm{~m}^{2}$. Essa abertura tornou possível a instalação dos loteamentos Cidade Cauype e Kauai. O desrespeito as áreas de preservação em torno do Lagamar do Cauype são tão grandes que as imagens publicitárias do primeiro mostram até a transformação de suas margens em uma praia artificial, modificando totalmente o ecossistema local (ver Figura 04).

Contudo, essas imagens publicitárias, apesar de terem papel fundamental na realização desses empreendimentos, podem não corresponder ao que foi aprovado na realidade. Por isso, é possível averiguar com segurança apenas a legalidade dos parâmetros urbanísticos como área e dimensões mínimas do lote e gabarito máximo das edificações. Nesse aspecto, todos os empreendimentos obedecem às orientações de área mínima do lote de $125 \mathrm{~m}^{2}$ e frente mínima de 5m, índices estipulados igualmente tanto pelo PDP-SGA quanto pelo PDDU-Caucaia.

\footnotetext{
${ }^{11}$ De acordo com a entrevista realizada com Renato Pequeno, ex funcionário do PPAU, em 18/06/2018.
} 
Outro exemplo de flexibilização dos Planos Diretores se refere à delimitação das zonas urbanas dos municípios. Percebe-se que as zonas urbanas de Caucaia e SGA foram desenhadas considerando a vinda do CIPP e o futuro interesse do mercado imobiliário sobre suas terras. Em Caucaia, a zona urbana pré-PDDU de 2001 era composta apenas pelas áreas conurbadas à Fortaleza e foi aumentada consideravelmente em direção ao porto (ver Figura 05), mesmo que na época não houvesse justificativa para tanto, além da previsão da sua valorização por causa do complexo. Já em SGA, 2/3 do município foi marcado no PDP-SGA como zona urbana ou de expansão, mesmo estando em sua maior parte desocupado. Tais delimitações excessivas de terras urbanas contribuem para o crescimento desordenado destes municípios, agredindo áreas que deveriam ser preservadas.

Figura 04: Loteamento Cidade Cauype e as margens do Lagamar do Cauype.

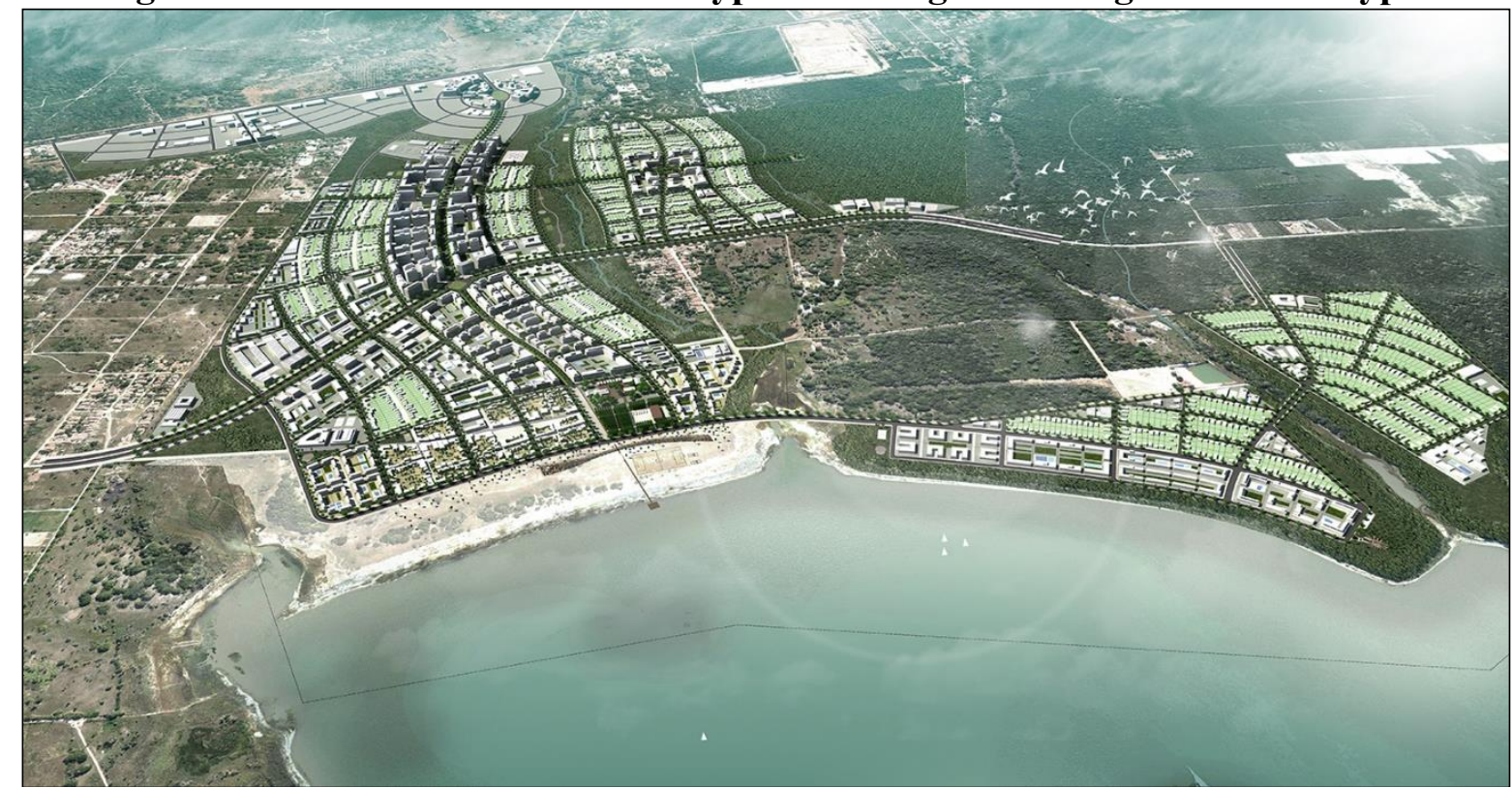

Fonte: Site oficial do Arquiteto Jaime Lerner disponível em"<http://jaimelerner.com.br/pt/portfolio/cidadecauype/>. Acesso em: 31 out. 2018.

Adensar áreas urbanas apenas ao redor de núcleos já consolidados pode gerar economia na construção de a infraestrutura e equipamentos urbanos para os bolsos do governo (KLUG, HAYASHI, 2012). Essa lógica de certa forma existe no Plano Diretor dos dois municípios, com indicações no zoneamento de quais áreas urbanas deveriam ser mais adensadas, entretanto não há uma efetiva restrição da ocupação. Como é interesse do mercado imobiliário buscar terras mais baratas para gerar um lucro maior (REIS FILHO, 2006), empreendimentos foram construídos irresponsavelmente em áreas consideradas como zona de expansão futura, por isso 
ainda ermas. Um exemplo disso é o empreendimento de 330ha Smart City Laguna que se instalou no distrito do Croatá e que pode atrair até 25 mil novos habitantes para um povoado habitado na época por apenas 6.400 habitantes, composto principalmente por agricultores, com “nível de urbanização é precário, sendo sua única via asfaltada a BR-222. Há energia elétrica, mas o abastecimento d'água é irregular. Não há esgotamento sanitário. A maioria das edificações possuem fossa séptica e as demais lançam os dejetos a céu aberto" (ASSEMBLEIA LEGISLATIVA DO ESTADO DO CEARÁ; CONSELHO DE ALTOS ESTUDOS E ASSUNTOS ESTRATÉGICOS; SANTANA, 2013, p. 135).

Figura 05: Evolução da mancha urbana (em amarelo) em Caucaia com o PDDU de 2001.

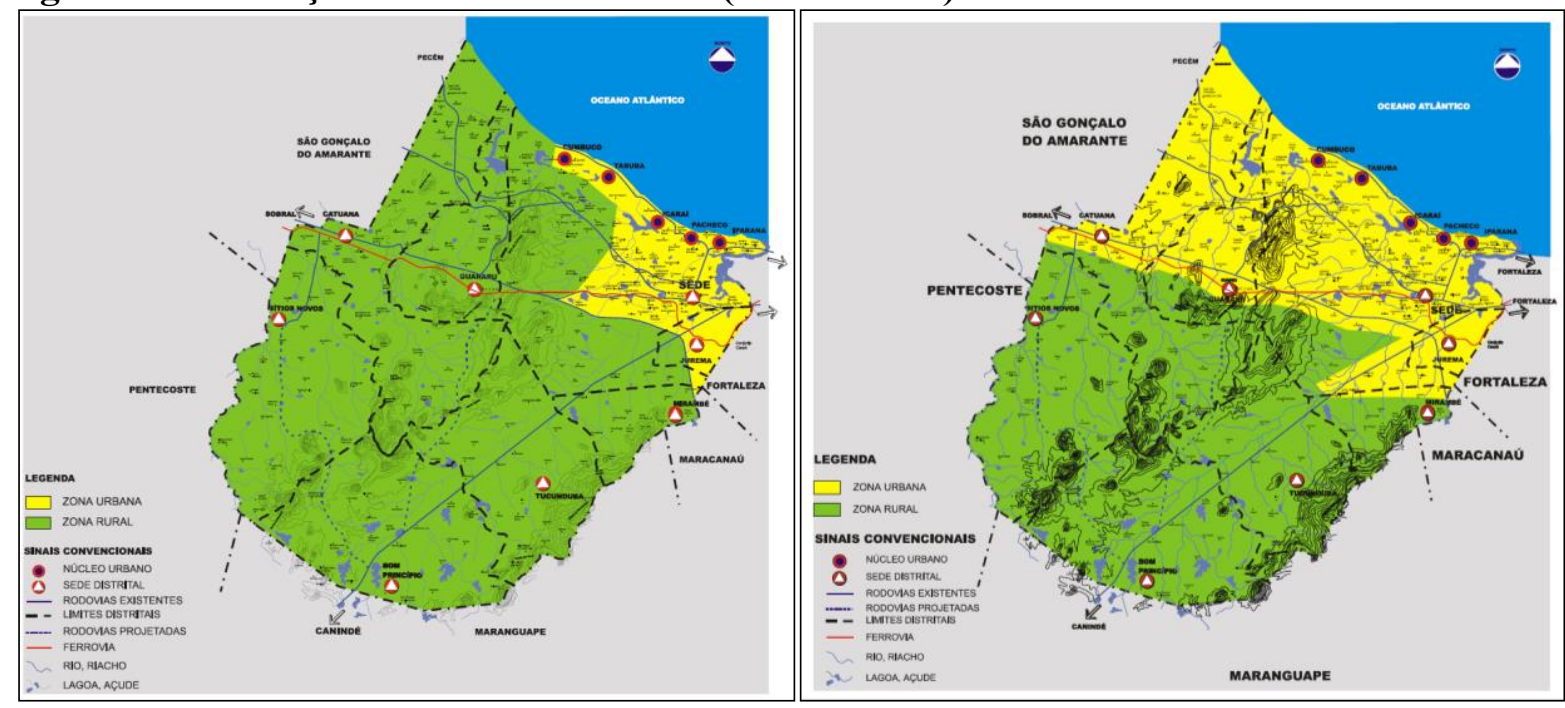

Fonte: PDDU-Caucaia 2001, Caderno do Plano de Estruturação Urbana, p. 20 e 21.

Se torna, então, difícil avaliar o grau de interação dos empreendimentos com o tecido urbano pré-existente, já que não existe nenhum. Geralmente loteamentos e condomínios fechados se distribuíram ao longo de rodovias por serem os principais elementos estruturantes da região, se tornando muitas vezes essas CEs ou BRs suas únicas ligações com a malha urbana. Por exemplo, o Residencial Roma pretende implantar pelo menos 6000 pessoas em uma área de 77ha conectada à CE-085 por apenas uma estreita via de mão dupla.

Em vários pontos do PDP-SGA percebe-se um esforço de estimular o desenvolvimento urbano adensado ao redor dos pequenos 
transporte público, promovendo a descentralização do trabalho e reduzindo os custos de transporte para seus habitantes (SÃO GONÇALO DO AMARANTE, 2014, p. 14).

E de fato alguns loteamentos buscam seguir essa lógica, como é o caso do Smart City Laguna, no qual um dos grandes elementos publicitários na sua estratégia de marketing é a questão de que o loteamento apresentará diversidade de usos e que será possível morar próximo ao trabalho. Entretanto, grande parte dos loteamentos no município ainda seguem o modelo mais tradicional de parcelamento do solo, atendendo apenas os parâmetros mínimos indicados pela lei $\mathrm{n}^{0} 6.766$ de 1979, ignorando os princípios de ordenamento territorial do PDP-SGA. Já no caso dos condomínios fechados e de edificações presentes em SGA, não há nem mesmo parâmetros para serem seguidos já que o próprio PDP-SGA se abstém de defini-los.

\section{CONSIDERAÇÕES FINAIS}

Após as evidências apresentadas nos itens anteriores deste trabalho, conclui-se que a entrada e permanência do mercado imobiliário na região foram facilitadas por um governo local afinado com os interesses dos agentes econômicos, que buscam principalmente expandir e acumular capital através da forma mais simples possível: a capitalização de um pedaço de terra parcelada em lotes. SGA e Caucaia se mostram como um novo eixo de expansão na RMF, a partir do qual se ampliam as fronteiras de atuação desse grupo, enquanto os Planos Diretores dos municípios flexibilizam e facilitam a sua instalação no entorno do CIPP ao flexibilizar a legislação em pontos específicos e convenientes. Um outro indício que confirma este entendimento é a proximidade dos Planos Diretores ao Planejamento Estratégico, já que a obrigatoriedade desses municípios em ter de realiza-lo como parte dos PDDUs $^{12}$ é muito significativo considerando que é uma forma de enxergar a cidade como um negócio passível de lucro, além de afirmar a lógica da competição entre as cidades, ao invés de considerar as possibilidades de cooperação entre as mesmas.

De fato, essa é uma questão chave: sabemos que o CIPP, como encadeador de processos em diversas escalas, exige que as instâncias governamentais colaborem entre si para maior eficiência do planejamento do que ocorre no complexo e em seu entorno e da mitigação de impactos que ele poderia causar. Entretanto, existem vários conflitos entre os planos, o que se agrava ainda mais com a fragilidade da gestão municipal de SGA e Caucaia que anseiam por desenvolver-se economicamente a qualquer custo. A esfera estadual se torna, então, soberana

\footnotetext{
${ }^{12}$ De acordo com entrevista com Renato Pequeno, ex funcionário do PPAU, realizada em 18/06/2019.
} 
na gestão do território sobre uma visão intermunicipal e não partilha a discussão com as secretarias locais de meio ambiente e urbanismo. Aparentemente, a busca pelo crescimento econômico e o desejo de manter a parceria com os agentes imobiliários é o único elemento que mantém as esferas unidas, abrindo ainda mais espaço para que as normativas se adequem aos desejos do mercado.

Perceber a importância da intersetorialidade intermunicipal, contudo, não é novidade: a sua ausência nas regiões metropolitanas brasileiras no geral foi exposta inclusive na Lei $\mathrm{n}^{\circ}$ 13.089 de 2015, também conhecida por Estatuto da Metrópole, que procura fornecer

(...) diretrizes gerais para o planejamento, a gestão e a execução das funções públicas de interesse comum em regiões metropolitanas e em aglomerações urbanas instituídas pelos Estados, normas gerais sobre o plano de desenvolvimento urbano integrado e outros instrumentos de governança interfederativa (BRASIL, 2015, art. $1^{\circ}$ ).

A partir daí, conclui-se que esta questão vai muito além dos instrumentos legislativos: é preciso, primeiramente, que uma nova forma de gestão seja pensada. Integrada, inter e multiescalar, ela deve garantir uma efetiva comunicação entre os órgãos, pensando o espaço como um só, e não fragmentos desmembrados por limites municipais. E sem dúvida, essa gestão precisa priorizar a produção de uma cidade justa, atenta à preservação ambiental e às demandas reais da população, ao invés de favorecer os interesses de um grupo que só está interessado na rentabilidade de seus empreendimentos.

\section{REFERÊNCIAS}

AALBERS, Manuel B. "Regulated deregulation”. In: SPRINGER, S.; BIRCH, K.; MACLEAVY, J. (Org.). Handbook of Neoliberalism. Londres: Routledge, 2016, p. 563-573

AALBERS, Manuel B. “The potential for financialization”. Dialogues in Human Geography, v. 5, n. 2, p. 214-219, 2015.

cASSEMBLEIA LEGISLATIVA DO ESTADO DO CEARÁ; CONSELHO DE ALTOS ESTUDOS E ASSUNTOS ESTRATÉGICOS; SANTANA, E. W. de (Org.). Cenário Atual do Complexo Industrial e Portuário do Pecém. Fortaleza: INESP, 2013.

ASSOCIAÇÃO DAS EMPRESAS DO COMPLEXO INDUSTRIAL E PORTUÁRIO DO PECÉM - AECIPP. Infraestrutura CIPP: A nova ordem industrial e logística do Ceará. s.d. Disponível em: 〈http://www.aecipp.com.br/pt-br/cipp〉. Acesso em: 14 maio 2018. 
BRASIL. Lei n ${ }^{\circ} 10.257$, de 10 de julho de 2001. Estatuto da Cidade. Brasília. Disponível em: $<$ http://www.planalto.gov.br/ccivil_03/leis/LEIS_2001/L10257.htm>. Acesso em: 01 nov. 2018 .

BRASIL. Lei n ${ }^{\circ} 13.089$, de 2015. Estatuto da Metrópole. Brasília. Disponível em: <http://www.planalto.gov.br/ccivil_03/_ato2015-2018/2015/lei/113089.htm>. Acesso em: 14 mai. 2018.

CAUCAIA. Caderno do Plano de Estruturação Urbana. Plano Diretor de Desenvolvimento Urbano de Caucaia. Caucaia- CE, 2013.

COMPANHIA DE INTEGRAÇÃO PORTUÁRIA DO CEARÁ - CEARÁPORTOS. Porto do Pecém mantém crescimento e exportações sobem 243\%. 2017. Disponível em: $<$ http://www.cearaportos.ce.gov.br/index.php/informacoes/listanoticias/786-porto-do-pecemmantem-crescimento-e-exportacoes-sobem-243>. Acesso em: 30 out. 2018.

GELERT, P. K.; LYNCH, B. D. "Mega-projects as displacements". International Social Science Journal, v. 55, n.175, p. 15-25, 2003.

JORNAL O POVO. Anuário do Ceará 2018-2019: Empresas no porto do Pecém (2017). 2018. Disponível em: <http://www.anuariodoceara.com.br/empresas-no-porto-do-pecemceara/>. Acesso em: 30 out. 2018.

KLUG, Stefan; HAYASHI, Yoshitsugu. "Urban Sprawl and Local Infrastructure in Japan and Germany”. Journal of infrastructure systems, v. 18 , p. 232-241, dez. 2012.

NOVAIS, Pedro. Uma estratégia chamada "Planejamento Estratégico": Deslocamentos espaciais e atribuição de sentidos na teoria do planejamento urbano. Rio de Janeiro: 7letras, 2010.

OLIVEIRA, Isabel C. E. de. Estatuto da cidade: para compreender. Rio de Janeiro: IBAM/DUMA, 2001.

PEYRELONGUE, Carlos D. M. "Puertos, espacio y globalización: eldesarrollo de hubs en México.” Convergencia, v. 52, p. 319-360, 2010.

REIS FILHO, Nestor Goulart. Notas sobre Urbanização dispersas e notas formas de tecido Urbano. São Paulo, SP: Via das Artes, 2006.

ROLNIK, Raquel. Guerra dos Lugares: A colonização da terra e da moradia na era das finanças. São Paulo: Boitempo, 2015.

ROSA, Sara Vieira; PEQUENO, Luís Renato Bezerra, NASSIF, Thais; LAGE, Mauricio; LIMA, Pedro. "Regulação para desregulamentação: Novos e Velhos Instrumentos Urbanísticos". In: ROLNIK, Raquel; SANTORO, Paula Freire; NASCIMENTO, Denise Morado; DE FREITAS, Daniel Medeiros; RENA, Natacha; PEQUENO, Luis Renato Bezerra (Orgs.) Cidade Estado Capital. São Paulo: FAUUSP, 2018, p. 83-115.

RUFINO, Maria Beatriz Cruz. Incorporação da Metrópole: Transformações na produção imobiliária e do espaço na Fortaleza do Século XXI. São Paulo: Annablume, 2016. 
SÃO GONÇALO DO AMARANTE. Código de Obras e Edificações. Plano Diretor Participativo do Município de São Gonçalo do Amarante. São Gonçalo do Amarante - CE. 2013.

TOPALOV, Christian. La Urbanización capitalista: algunos elementos para su análisis. México: Edicol, 1979.

Recebido em Abril de 2019

Aprovado em Julho de 2019

Publicado em Agosto de 2019 